\title{
Use of Insulin in treatment of COVID-19: A proposal to explore feasibility
}

\author{
Authors \\ Dr Jayesh G Kalbhande ${ }^{1}$, Dr Vicky Kuldeep ${ }^{2}$ \\ ${ }^{1}$ Consultant Surgeon, BARC Hospital \\ ${ }^{2}$ DNB General Surgery \\ Corresponding Author \\ Dr Jayesh G Kalbhande
}

\section{Introduction}

It was December 2019, first case of Corona Virus Disease 2019 viz. Covid-19 was reported in Wuhan, China. ${ }^{(1)}$ Initially the Chinese Centre of Disease Control and Prevention (CDC) named it as Severe Acute Respiratory Syndrome Coronavirus 2 which was later labelled as COVID-19 by WHO on February 11, 2020. ${ }^{(2)}$ Soon COVID-19 was declared as Pandemic by WHO. COVID-19 symptoms include fever, dry cough, muscle pain, diarrhoea, fatigue, loss of smell and taste. It has been found that it can lead to sudden and rapid deterioration in general condition resulting in respiratory failure and septic shock in severe cases. ${ }^{(3)}$

COVID 19 has a major impact in European countries and in United States of America. Presently there are more than 15 million cases worldwide with a death toll of more than0.6 million. ${ }^{(4)}$ Currently the number of COVID 19 positive cases is rapidly rising in India. As of today, there is no curative medication for COVID 19.Patients with mild symptoms recovers with supportive medication. Patients with moderate to severe symptoms, especially the elderly or with comorbidities may develop severe COVID 19.
They are currently treated with number of experimental and repurposed medications. These patients may have high mortality rates. ${ }^{(5)} \mathrm{We}$ scrolled through the literature to analyse the role of Insulin in the treatment of COVID-19.

\section{Discussion}

Mortality count of COVID-19 is in lakhs and found to be higher among elderly. According to a study, mean age of COVID-19 patients in China was found to be 58 years and $52 \%$ were men. On comparison with non-severe group of patients, severe group of patients were significantly older with mean age of 61 years. ${ }^{(6)}$ Centre for Disease Control and Prevention data show that mortality of COVID-19 increases with advancing age. ${ }^{(7)}$ These findings suggest that mortality related to COVID 19 is the least in younger age group and it increases with age. In 2013, SARS had similar pattern in mortality.

SARS-CoV-2 has approximately 80\% similarity with genome of SARS-CoV. ${ }^{(8)}$ Mortality rates is SARS had similar trend as that of COVID 19. According to World health organisation, Age specific case fatality ration caused by SARS in China was 20-29 years $-0.9 \%$, 30-39 years- $3.0 \%$, 
40-49 years- 5.0\%, 50-59 years- 10\%, 60-69 years- $17.6 \%, 70-79$ years- $28 \%$ and $80+$ years $26.3 \%$. ${ }^{(9)}$ These findings exemplify that mortality related to SARS is highest in elderly and least in young which has similarity with mortality related to COVID 19.

If the pathophysiology of this epidemiological distribution is correctly understood, it will have implications on treatment and control of COVID 19 pandemic. We scrolled through literature for analysis of HbA1c levels in nondiabetic population which showed an interesting finding. It was found that mean $\mathrm{HbA} 1 \mathrm{c}$ of population was least at young age and it gradually increased with increasing age. One of the many factors in this finding could be decrease in muscle mass with advancing age which may resulting in underutilisation of glucose. Tissue sensitivity to insulin decreases with increasing age, result in insulin resistance. ${ }^{(10)(11)(12)}$ Young and nondiabetic population has low HbA1c as seen in a study by Saaddine JB et al, wherein it was reported that mean HbA1c among a group of nondiabetic young Americans between 5-24 years was found to be 4.99\%.(13)Roth J. et al also found mean HbA1c of age groups $<30$ was $4.98 \%$, 30-40 was $5.07 \%$, $40-50$ was $5.17 \%$, , 50-60 was $5.33 \%, 60-70$ was $5.42 \%$ and more than 70 years had HbA1c of $5.45 \%$. This suggests a gradual increase in HbA1c with age. Youngest have the lowest HBA1c. This may correlate with robust secretion of insulin from pancreas and good sensitivity of tissue to insulin. ${ }^{(14)} \mathrm{HbA} 1 \mathrm{c}$ is indicates average blood sugar over last 3 months. Average blood sugar is an indirect indicator of insulin activity in our body. With age insulin resistance creeps in which contributes to increased $\mathrm{HbA1c}$ with age.

The mortality related to COVID 19 infection increases with age and average HbA1c of general population also increases with age. HbA1c is indirect reflection of blood sugar and insulin activity in our body. Diabetic patients are likely to have more severe COVID 19 disease. This is provides support to the hypothesis that insulin resistance may be a major driver in severity of
COVID 19. We propose insulin resistance and severity of COVID 19 infection may be linked to each other so much so that it may have cause and effect relationship. We further explored the possible association of insulin and COVID 19. We found several pointers in the literature which will support a strong relationship between insulin and COVID 19.

Angiotensin-converting enzyme 2 (ACE2) has been discovered as a functional receptor for corona viruses, including SARS-CoV ${ }^{(15)}$ and SARS-CoV-2. ${ }^{(16)}$ SARS-CoV-2 infection is triggered by binding of the spike protein of the virus to ACE2, which is highly expressed in the heart and lungs. SARS-CoV-2 mainly invades alveolar epithelial cells, resulting in respiratory symptoms. ${ }^{(15)}$ ACE2 is a membrane- bound aminopeptidase discovered in 2000 and plays a pivotal role in RAS. ${ }^{(16)}$ The Renin- Angiotensin System (RAS) is a critical homeostasis regulation system of the human body. ACE2 is homologous with ACE, although they have entirely different functions. ${ }^{(17)(18)}$ ACE2 pathway is actually a counter regulatory pathway against angiotensin II. Angiotensin II pathway plays important role in development of hypertension, heart failure and obesity. ACE2 pathway physiologically gets activated to decrease damage caused by Angiotensin II. ACE2 receptor being entry point of SARS COV 2, increased activation of ACE2 receptors in patients with hypertension, heart failure and obesity may be a important etiology for severe COVID 19 infection seen in these high risk group. ${ }^{(19)}$

Marta Riera et al in their experiment on non-obese diabetic mice model found that there was increase in circulating and urine ACE2 activity in Diabetic mice. On controlling sugars with insulin there was a decrease in ACE2 activity. ${ }^{(20)}$ In another study it was found that ACE2 activity is increased in Type I diabetic patients having heart, vascular and kidney diseases. ${ }^{(21)}$ Salem ES et al in their experiment on diabetic Akita mice found that they had increased ACE 2 activity in urine. Treatment of Akita mice with insulin normalized 
hyperglycaemia and decreased urinary ACE2. ${ }^{(22)}$ These experiments showed that there is an inverse relationship between insulin and ACE2 receptor and treatment with insulin resulted in lowering of ACE2 receptors.

Mortality caused by COVID 19 is least in children and increases with age. HbA1c is lowest in children and increases with age. Both patterns of age-related rise in mortality caused by COVID 19 and age-related rise in $\mathrm{HbA} 1 \mathrm{c}$ matches each other. Lower HbA1c in children is because of greater insulin sensitivity. As insulin has inverse relationship with ACE2 receptors, it is natural that children would have low ACE2 receptors. This may be most likely pathophysiology of in less severe COVID 19 infection in children. Therefore, we propose that both, rising HbA1c with age and rising mortality with age, are causally related and significantly lower $\mathrm{HbA1c}$ in children as compared to adults protects the children from severe COVID 19 and results in almost negligible mortality. A similar thought process was expressed by Luca Cristiani et al. who proposed an ACE2 receptor based mechanism protecting children from severe COVID 19. ${ }^{(23)}$

In another article Adam Brufsky et al proposed that, hyperglycemia may increase the affinity of SARS COV 2 to ACE2 receptors and this may result in proliferation of virus and increased severity of infection. It was postulated that hyperglycaemia by itself, in diabetic as well as nondiabetic patients, may lead to glycosylation of ACE2 receptors, which may in turn increase the affinity towards SARS CoV-2 resulting into severe infection. ${ }^{(24)}$ A. Ceriello suggested that treatment of hyperglycaemia and lowering of blood sugar in diabetic as well as nondiabetic patients may act by decreasing the binding of SARS COV 2 to ACE2 receptors and it may result in improved prognosis in COVID 19. ${ }^{(25)}$

In summary insulin may have important role in treatment of COVID 19 way of decreasing ACE-2 receptors and decreased glycosylation of ACE-2 receptors resulting in decreased binding of ACE2 receptors to SARS COV 2. However in addition to these benefits, insulin may have multiple benefits in treatment of critically ill patients as follows.

Diabetes and hyperglycemia results in immunocompromised state because of poor functioning of neutrophils. There is impaired phagocytosis, decreased chemotaxis and impaired intracellular killing. This causes diabetic and hyperglycaemic individuals to become increasingly susceptible to infection. (26)(27)(28)(29)(30)(31)(32)(33)(34) The corollary of same is that if hyperglycemia is controlled with insulin, it would improve the immunocompromised status, improve chemotaxis and it will help in reduction of infection. ${ }^{(31)}$ In a study, it was observed that aggressive blood sugar control to 150 to $200 \mathrm{mg} / \mathrm{dl}$, by insulin infusion resulted in decrease in infection by $60 \% .^{(35)}$

Critically ill patients are having hyperglycaemia which can be multifactorial in origin. Hyperglycaemia leads to increased activation of immune system which in turn leads to release of numerous inflammatory mediators, cytokines. These inflammatory molecules lead to organ damage. ${ }^{(36)(37)(38)(39)}$ In an experimental model it was found that administration of insulin resulted in decrease in inflammatory molecules. (36)(40)(41)(42) Thus insulin has a potential role in reducing the ill effect of inflammatory molecules which leads to cytokine storm and multiorgan failure.

Van Den Bergh, in a randomized controlled trial in critically ill patients demonstrated that strict control of blood sugar between 70 to $110 \mathrm{mg} / \mathrm{dl}$ resulted in significantly lower morbidity and mortality. ${ }^{(43)}$ NICE sugar trial reported that blood sugar control up to $180 \mathrm{mg} / \mathrm{dl}$ may result in improved outcome in critically ill patients as compared to very low level of blood sugar control of 80 to $108 \mathrm{mg} / \mathrm{dl}$. NICE sugar trial used regular human insulin infusion for control of blood sugar. ${ }^{(44)}$ In NICE sugar trial it was found that intensive blood sugar control arm had higher incidence of hypoglycaemia. Human regular insulin has delayed peak action of 2-4 hours and long duration of action of 6-8 hour, whichmay 
have led to cumulative action of human regular insulin when given in infusion form. This has inherent potential of causing hypoglycaemic events. This may be a likely mechanism of hypoglycaemia in intensive sugar control arm in NICE sugar study.

Long acting insulin analogue like Glargine has uniform action over a period of 24 hours. It do not have slow rise and delayed peak action as seen in human regular insulin. This property of Glargine insulin makes it a suitable medication to be used in treatment of hyperglycemia in intensive care unit. Although in different setting, it was found that Glargine insulin is associated with lesser chances of hypoglycaemia as compared to conventional insulin for intensive insulin therapy. ${ }^{(45)}$ Use of Glargine insulin in critical care set up only one study was found. In a study of 110 critically ill patients it was found that addition of Glargine insulin 15 Units to insulin infusion protocol improved the glycaemic control significantly. ${ }^{(46)}$ In this study Glargine insulin was used in addition to human regular insulin infusion which again has delayed peak action and potential for causing hypoglycaemia. This study was also no exception to it. There was higher incidence of hypoglycaemia in this study as well.

To summarize, insulin may lower ACE 2 receptors thus causing decreased entry of SARS COV2 in to cells and acting on the first step of COVID 19 infection. Lowering of blood glucose by insulin may decrease binding of SARS COV2 to ACE2 receptors by causing decreased glycosylation of ACE2 receptors. Insulin may improve immunity by increasing chemotaxis and by increased intracellular killing of viruses. Insulin has potential to reduce cytokine storm caused by inflammatory mediators by decreasing the formation of inflammatory mediators. Insulin is likely to be one of the most effective treatments of COVID 19 in diabetic as well as nondiabetic patients. It has a potential to change the course of COVID 19 pandemic. Long and uniform acting analogue insulin is likely to be better suitable option in treatment of COVID 19 than human regular insulin which has delayed peak action, shorter duration of action and higher potential for causing hypoglycaemia.

\section{Conclusion}

COVID 19 pandemic has potential to cause large number of deaths world over. There is no curative treatment available for COVID 19 at present. Insulin may have a potential therapeutic rolein treatment of COVID 19.We hypothesis that long acting analogue insulin such as Glargine insulin may be more effective than human regular insulin in the treatment of COVID 19. This may help in generation of hypothesis for future pilot study.

Declaration- We declare no conflict of interest.

\section{References}

1. Zhu N, Zhang D, Wang W, Li X, Yang B, Song $\mathrm{J}$, et al. A novel coronavirus from patients with pneumonia in China, 2019. N Engl J Med. 2020;

2. Lu R, Zhao X, Li J, Niu P, Yang B, Wu H, et al. Genomic characterisation and epidemiology of 2019 novel coronavirus: implications for virus origins and receptor binding. Lancet. 2020;395(10224):565-74.

3. Huang C, Wang Y, Li X, Ren L, Zhao J, $\mathrm{Hu} \mathrm{Y}$, et al. Clinical features of patients infected with 2019 novel coronavirus in Wuhan, China. Lancet. 2020;395 (10223):497-506.

4. WHO official website [Internet]. Available from: https://covid19.who.int

5. Wang D, Hu B, Hu C, Zhu F, Liu X, Zhang $\mathrm{J}$, et al. Clinical characteristics of 138 hospitalized patients with 2019 novel coronavirus-infected pneumonia in Wuhan, China. Jama. 2020;323(11):10619.

6. Qin C, Zhou L, Hu Z, Zhang S, Yang S, Tao $\mathrm{Y}$, et al. Dysregulation of immune response in patients with COVID-19 in Wuhan, China. Clin Infect Dis. 2020;

7. Centre for Disease Control and Prevention 
[Internet]. Available from: https://www.cdc.gov/nchs/nvss/vsrr/COVI D19/

8. Chan JF-W, Kok K-H, Zhu Z, Chu H, To KK-W, Yuan S, et al. Genomic characterization of the 2019 novel humanpathogenic coronavirus isolated from a patient with atypical pneumonia after visiting Wuhan. Emerg Microbes Infect. 2020;9(1):221-36.

9. Organization WH. Consensus document on the epidemiology of severe acute respiratory syndrome (SARS). World Health Organization; 2003.

10. Pani LN, Korenda L, Meigs JB, Driver C, Chamany S, Fox CS, et al. Effect of aging on A1C levels in individuals without diabetes: evidence from the Framingham Offspring Study and the National Health and Nutrition Examination Survey 20012004. Diabetes Care. 2008;31(10):1991-6.

11. Sacks DB, Arnold M, Bakris GL, Bruns DE, Horvath AR, Kirkman MS, et al. Guidelines and recommendations for laboratory analysis in the diagnosis and management of diabetes mellitus. Clin Chem. 2011;57(6):e1-47.

12. Dubowitz N, Xue W, Long Q, Ownby JG, Olson DE, Barb D, et al. Aging is associated with increased HbA1c levels, independently of glucose levels and insulin resistance, and also with decreased $\mathrm{HbAlc}$ diagnostic specificity. Diabet Med. 2014;31(8):927-35.

13. Saaddine JB, Fagot-Campagna A, Rolka D, Narayan KMV, Geiss L, Eberhardt M, et al. Distribution of HbA1c levels for children and young adults in the US: Third National Health and Nutrition Examination Survey. Diabetes Care. 2002;25(8):1326-30.

14. Roth J, Müller N, Lehmann T, Heinemann L, Wolf G, Müller UA. HbA1c and age in non-diabetic subjects: an ignored association? Exp Clin Endocrinol
Diabetes. 2016;124(10):637-42.

15. Turner AJ, Hiscox JA, Hooper NM. ACE2: from vasopeptidase to SARS virus receptor. Trends Pharmacol Sci. 2004;25(6):291-4.

16. Hoffmann M, Kleine-Weber H, Schroeder $S$, Krüger N, Herrler T, Erichsen $S$, et al. SARS-CoV-2 cell entry depends on ACE2 and TMPRSS2 and is blocked by a clinically proven protease inhibitor. Cell. 2020;

17. Donoghue M, Hsieh F, Baronas E, Godbout K, Gosselin M, Stagliano N, et al. A novel angiotensin-converting enzymerelated carboxypeptidase (ACE2) converts angiotensin I to angiotensin 1-9. Circ Res. 2000;87(5):e1-9.

18. Tikellis C, Bernardi S, Burns WC. Angiotensin-converting enzyme 2 is a key modulator of the renin-angiotensin system in cardiovascular and renal disease. Curr Opin Nephrol Hypertens. 2011;20(1):628.

19. Patel VB, Mori J, McLean BA, Basu R, Das SK, Ramprasath $\mathrm{T}$, et al. ACE2 deficiency worsens epicardial adipose tissue inflammation and cardiac dysfunction in response to diet-induced obesity. Diabetes. 2016;65(1):85-95.

20. Riera Oliva M, Márquez E, Clotet S, Gimeno J, Roca-Ho H, Lloreta Trull J, et al. Effect of insulin on ACE2 activity and kidney function in the non-obese diabetic mouse (PLoS ONE (2014)). PLoS ONE 2014; 9 e84683. 2014;

21. Soro-Paavonen A, Gordin D, Forsblom C, Rosengard-Barlund M, Waden J, Thorn L, et al. Circulating ACE2 activity is increased in patients with type 1 diabetes and vascular complications. J Hypertens. 2012;30(2):375-83.

22. Salem ESB, Grobe N, Elased KM. Insulin treatment attenuates renal ADAM17 and ACE2 shedding in diabetic Akita mice. Am J Physiol Physiol. 2014;306(6):F629- 
39.

23. Cristiani L, Mancino E, Matera L, Nenna R, Pierangeli A, Scagnolari C, et al. Will children reveal their secret? The coronavirus dilemma. Eur Respiratory Soc; 2020.

24. Brufsky A. Hyperglycemia, hydroxychloroquine, and the COVID- 19 pandemic. J Med Virol. 2020;

25. Ceriello A. Hyperglycemia and the worse prognosis of COVID-19. Why a fast blood glucose control should be mandatory. Diabetes Res Clin Pract. 2020;

26. Zhou T, Hu Z, Yang S, Sun L, Yu Z, Wang G. Role of adaptive and innate immunity in type 2 diabetes mellitus. J Diabetes Res. 2018;2018.

27. Geerlings SE, Hoepelman AIM. Immune dysfunction in patients with diabetes mellitus (DM). FEMS Immunol Med Microbiol. 1999;26(3-4):259-65.

28. Moutschen MP, Scheen AJ, Lefebvre PJ. Impaired immune responses in diabetes mellitus: analysis of the factors and mechanisms involved. Relevance to the increased susceptibility of diabetic patients to specific infections. Diabete Metab. 1992;18(3):187.

29. Tan JS, Anderson JL, Watanakunakorn C, Phair JP. Neutrophil dysfunction in diabetes mellitus. J Lab Clin Med. 1975;85(1):26-33.

30. Gin H, Brottier E, Aubertin J. Influence of glycaemic normalisation by an artificial pancreas on phagocytic and bactericidal functions of granulocytes in insulin dependent diabetic patients. J Clin Pathol. 1984;37(9):1029-31.

31. Mowat AG, Baum J. Chemotaxis of polymorphonuclear leukocytes from patients with diabetes mellitus. N Engl J Med. 1971;284(12):621-7.

32. Sima AAF, O'Neill SJ, Naimark D, Yagihashi S, Klass D. Bacterial phagocytosis and intracellular killing by alveolar macrophages in BB rats. Diabetes. 1988;37(5):544-9.

33. Nolan CM, Beaty HN, Bagdade JD. Further characterization of the impaired bactericidal function of granulocytes in patients with poorly controlled diabetes. Diabetes. 1978;27(9):889-94.

34. Pozzilli P, Leslie RDG. Infections and diabetes: mechanisms and prospects for prevention. Diabet Med. 1994;11(10):93541.

35. Furnary AP, Zerr KJ, Grunkemeier GL, Starr A. Continuous intravenous insulin infusion reduces the incidence of deep sternal wound infection in diabetic patients after cardiac surgical procedures. Ann Thorac Surg. 1999;67(2):352-60.

36. Sun Q, Li J, Gao F. New insights into insulin: The anti-inflammatory effect and its clinical relevance. World J Diabetes. 2014;5(2):89.

37. Yorek MA, Dunlap JA. Effect of increased concentration of D-glucose or L-fucose on monocyte adhesion to endothelial cell monolayers and activation of nuclear factor-[kappa] B. Metab Exp. 2002;51(2):225-34.

38. Nishikawa T, Edelstein D, Du XL, Yamagishi S, Matsumura T, Kaneda Y, et al. Normalizing mitochondrial superoxide production blocks three pathways of hyperglycaemic damage. Nature. 2000;404(6779):787-90.

39. Morigi M, Angioletti S, Imberti B, Donadelli R, Micheletti G, Figliuzzi M, et al. Leukocyte-endothelial interaction is augmented by high glucose concentrations and hyperglycemia in a NF-kB-dependent fashion. J Clin Invest. 1998;101(9):190515.

40. Aljada A, Saadeh R, Assian E, Ghanim H, Dandona P. Insulin inhibits the expression of intercellular adhesion molecule-1 by human aortic endothelial cells through stimulation of nitric oxide. J Clin 
Endocrinol Metab. 2000;85(7):2572-5.

41. Dandona P, Aljada A, Mohanty P, Ghanim $\mathrm{H}$, Hamouda W, Assian E, et al. Insulin inhibits intranuclear nuclear factor $\kappa \mathrm{B}$ and stimulates $\mathrm{I} \kappa \mathrm{B}$ in mononuclear cells in obese subjects: evidence for an antiinflammatory effect? J Clin Endocrinol Metab. 2001;86(7):3257-65.

42. Aljada A, Ghanim H, Mohanty P, Kapur $\mathrm{N}$, Dandona P. Insulin inhibits the proinflammatory transcription factor early growth response gene-1 (Egr)-1 expression in mononuclear cells (MNC) and reduces plasma tissue factor (TF) and plasminogen activator inhibitor-1

(PAI-1) concentrations. J Clin Endocrinol Metab. 2002;87(3):1419-22.

43. Van den Berghe G, Wouters P, Weekers F, Verwaest C, Bruyninckx F, Schetz M, et al. Intensive insulin therapy in critically ill patients. N Engl J Med. 2001;345(19):1359-67.

44. Investigators N-SS. Intensive versus conventional glucose control in critically ill patients. N Engl J Med. 2009;360(13):1283-97.

45. Ratner RE, Hirsch IB, Neifing JL, Garg SK, Mecca TE, Wilson CA. Less hypoglycemia with insulin glargine in intensive insulin therapy for type 1 diabetes. US Study Group of Insulin Glargine in Type 1 Diabetes. Diabetes Care. 2000;23(5):639-43.

46. Nader ND, Hamishehkar H, Naghizadeh A, Shadvar K, Iranpour A, Sanaie S, et al. Effect of Adding Insulin Glargine on Glycemic Control in Critically Ill Patients Admitted to Intensive Care Units: A Prospective Randomized Controlled Study. Diabetes, Metab Syndr Obes Targets Ther. 2020;13:671. 